\title{
Intrathecal Labor Analgesia Using Dexmedetomidine: A Viable Alternative to Epidural Analgesia
}

\author{
Sanjay Rathod ${ }^{1}$, Geetika G Syal ${ }^{2}$, Rajeev Sood ${ }^{3}$, Kartik Syal ${ }^{4}$
}

\begin{abstract}
Aims and objectives: The aims and objectives of the study were to compare the safety and efficacy of single dose intrathecal analgesia using bupivacaine and fentanyl with either dexmedetomidine or morphine on maternal and fetal outcome.

Materials and methods: One-hundred and twenty parturients with uncomplicated pregnancy in spontaneous or induced labor at cervical dilatation 4-6 cm were enrolled for the study. They were randomized into two groups of 60 each. Group I received dexmedetomidine $5 \mu \mathrm{g}$ $(1 \mathrm{~mL})$ and group II received morphine $250 \mu \mathrm{g}(1 \mathrm{~mL})$ along with $0.5 \%$ bupivacaine heavy $2.5 \mathrm{mg}(0.5 \mathrm{~mL})+$ Fentanyl $25 \mu \mathrm{g}(0.5 \mathrm{~mL})$. Progress of labor, duration of analgesia, and neonatal APGAR score was recorded and compared between the two groups.

Result: The mean rate of cervical dilatation in group I was $1.63 \pm 0.135 \mathrm{~cm} /$ hour whereas it was $1.54 \pm 0.156 \mathrm{~cm} / \mathrm{hour}$ in group II ( $p=0.001$ ). The mean total duration of labor in group I was $682.35 \pm 60.920$ minutes whereas it was $771.63 \pm 52.016$ minutes $(p=0.005)$. In the group I, $98.3 \%$ $(59 / 60)$ had NVD, $1.7 \%(1 / 60)$ had IVD, and none had cesarean delivery. Similarly 75\% (45/60) had NVD, 15\% (9/60) had IVD, and 10\% (6/60) had cesarean delivery in the group II. This difference was statistically significant $(p=0.001)$. However, duration of the second stage of labor, duration of labor analgesia, maternal satisfaction, and APGAR score did not differ in the two groups.

Conclusion: Single-shot intrathecal labor analgesia using combination of bupivacaine $(2.5 \mathrm{mg})$, fentanyl $(25 \mu \mathrm{g})$, and dexmedetomidine $(5 \mu \mathrm{g})$ is a safe, effective, reliable, cheap, and satisfactory method of pain relief for labor and delivery.

Keywords: Dexmedetomidine, Intrathecal analgesia, Labor analgesia.

Journal of South Asian Federation of Obstetrics and Gynaecology (2021): 10.5005/jp-journals-10006-1949
\end{abstract}

\section{INTRODUCTION}

Labor is a highly complex event. ' Labor pain is one of the most severe types of pain a woman will experience in her life time. Maternal pain and anxiety cause increase in release of catecholamines which in turn cause uncoordinated uterine contraction, reduced utero-placental blood flow, ${ }^{2}$ and may act as tocolytic. Hence effective pain relief with regional analgesia enhances uterine contractions and chances of causing dystocia decrease. ${ }^{3}$ There are many different techniques, both regional and nonregional, to provide labor analgesia. Currently, the gold standard obstetric analgesia is epidural anesthesia. But intrathecal labor analgesia is simple, easy, and effective method for painless and safe delivery. This can be used effectively as well as economically in low resource set-up for intrapartum pain relief. When the two drugs are combined, both the local anesthetic and opioid can be administered at low concentrations, resulting in increased maternal satisfaction and, most importantly, a decrease in the incidence of adverse effects such as hypotension and drug toxicity. ${ }^{2}$ Dexmedetomidine is a new selective $\alpha_{2}$-adrenoreceptor agonist that has sedative and anesthetic properties. It acts by activating proteins in the brain stem which results in the inhibition of norepinephrine release. It provides stable hemodynamic conditions, good quality of intraoperative, and prolonged postoperative analgesia with minimal side effects. Intrathecal DMT has been found to have antinociceptive action for both somatic and visceral pain. ${ }^{4,5}$ We therefore conducted study to compare the safety and efficacy of single-dose intrathecal analgesia using bupivacaine, fentanyl, and dexmedetomidine and bupivacaine with fentanyl and morphine on maternal and fetal outcome.

\footnotetext{
${ }^{1-3}$ Department of Obstetrics and Gynaecology, Indira Gandhi Medical College and Hospital, Shimla, Himachal Pradesh, India

${ }^{4}$ Department of Anaesthesia, Indira Gandhi Medical College and Hospital, Shimla, Himachal Pradesh, India

Corresponding Author: Kartik Syal, Department of Anaesthesia, Indira Gandhi Medical College and Hospital, Shimla, Himachal Pradesh, India, Phone: +919418485156, e-mail: dr.geetikagupta@gmail.com

How to cite this article: Rathod S, Syal GG, Sood R, et al. Intrathecal Labor Analgesia Using Dexmedetomidine: A Viable Alternative to Epidural Analgesia. J South Asian Feder Obst Gynae 2021;13(5):279-282. Source of support: Nil

Conflict of interest: None
}

\section{Aims and 0 bjectives}

\section{Aims}

To compare the effect of single-dose intrathecal analgesia on maternal and fetal outcome.

\section{Objectives}

To assess and compare maternal and fetal outcome after using intrathecal analgesia through

- Mode of delivery: Normal/Instrumental/Cesarean

- Duration of labor

- Average rate of progression of labor

- Effect on ambulation.

() The Author(s). 2021 Open Access This article is distributed under the terms of the Creative Commons Attribution 4.0 International License (https://creativecommons. org/licenses/by-nc/4.0/), which permits unrestricted use, distribution, and non-commercial reproduction in any medium, provided you give appropriate credit to the original author(s) and the source, provide a link to the Creative Commons license, and indicate if changes were made. The Creative Commons Public Domain Dedication waiver (http://creativecommons.org/publicdomain/zero/1.0/) applies to the data made available in this article, unless otherwise stated. 


\section{Materials and Methods}

A prospective, randomized controlled double-blind study was conducted at Kamla Nehru State Hospital for mother and child, Indira Gandhi Medical College (IGMC), to compare the effect of single-dose intrathecal analgesia using bupivacaine, fentanyl and dexmedetomidine, and bupivacaine with fentanyl and morphine on maternal and fetal outcome.

One-hundred and twenty laboring primigravida patients of age 20-35 years with singleton pregnancy at term with vertex presentation, scheduled for normal vaginal delivery and having cervical dilatation of 4-6 cm, desiring for labor analgesia, were recruited (between June 1, 2019 and December 31, 2019) after obtaining informed written consent and clearance from the institute ethics and research committee.

A thorough general physical examination was done. Per abdominal examination was done to confirm lie, presentation, and position. Duration, intensity, and frequency of uterine contractions were noted. Fetal heart sound was auscultated and noted. Per vaginal examination was done and cervical dilation, effacement, position, and station of the presenting part were noted. Pelvic assessment was done to rule out cephalopelvic disproportion (CPD). Artificial rupture of membranes (ARM) was done at $\geq 4 \mathrm{~cm}$ cervical dilatation and after confirming clear liquor case was selected for study. All parturients were subjected for basic investigations $(\mathrm{HB}$, ABORh, TSH, HIV, HBsAg, STS, $75 \mathrm{~g}$ OGTT) if not already done.

Computerized randomization software was used to divide cases who matched inclusion criteria into two groups. Selected parturients were randomly allocated into two groups. The study solutions were prepared by the anesthesiologist not involved in the study. The parturients of the two groups were given coded drugs. Code was broken after data assimilation. Maternal numerical pain rating score (NPRS) was recorded by the anesthetist.

Under all aseptic precautions parturients back were painted and draped. L3-L4 interspace was identified and overlying skin was infiltrated with $2 \mathrm{~mL}$ of $1 \%$ lignocaine. $26 \mathrm{G}$ spinal needle was introduced via median/para median approach. Correct placement of spinal needle in subarachnoid space was confirmed by free flow of cerebrospinal fluid and coded drugs were injected.

Parturients were kept in supine position for 10 minutes and then allowed to ambulate with assistance. Onset of analgesia was noted, which was taken as time in minutes needed to decrease in NPRS score during labor pain by 2 . Failure to achieve this was regarded as "Failed Block" and alternate measures of analgesia were administered and parturients were noted and dropped from further study.

In both the groups the following data were obtained every 5 minutes for first 30 minutes, then every 30 minutes until delivery:

- Maternal blood pressure

- Heart rate, respiratory rate

- Maternal NPRS score

- Effect on ambulation

- Other side effects like maternal nausea, vomiting, drowsiness, palpitations and pruritis

\begin{tabular}{ll}
\hline $\begin{array}{l}\text { Group l: received single shot of } \\
\text { intrathecal }\end{array}$ & $\begin{array}{l}\text { Group II: received single shot of } \\
\text { intrathecal }\end{array}$ \\
\hline $0.5 \mathrm{~mL}$ of $0.5 \%$ bupivacaine heavy & $0.5 \mathrm{~mL}$ of $0.5 \%$ bupivacaine \\
$(2.5 \mathrm{mg})$ with & $0.5 \%$ heavy $(2.5 \mathrm{mg})$ with \\
$0.5 \mathrm{~mL}$ fentanyl $(25 \mu \mathrm{g})$ and & $0.5 \mathrm{~mL}$ fentanyl $(25 \mu \mathrm{g})$ and \\
$1 \mathrm{~mL}$ of dexmedetomidine $(5 \mu \mathrm{g})$ & $1 \mathrm{~mL}$ morphine $(250 \mu \mathrm{g})$ \\
Total: $2 \mathrm{~mL}$ & Total: $2 \mathrm{~mL}$ \\
\hline
\end{tabular}

Fetal heart rate was monitored continuously using electronic fetal monitoring. The labor was monitored partographically. The third stage of labor was managed actively.

At delivery time, NPRS score and type of delivery were recorded. The indication for instrumental delivery (ventouse/forceps) or caesarean section was noted. Postdelivery maternal satisfaction was noted.

Neonatal assessment was done by assessing APGAR score at 1 and 5 minutes and needed resuscitation and NICU admissions.

\section{Observation and Results}

Demographic data like age, gestation, and mean cervical dilatation were statistically similar in both the groups. Mean cervical dilatation rate was found to be faster than normal pregnancy rate; being quicker in dexmedetomidine group. In our study we had only one instrumental vaginal delivery in dexmedetomidine group whereas there were nine instrumental vaginal deliveries in morphine group; on the other hand group I had no caesarean sections as compared to six in group II. These results were statistically significant. There was no difference in fetal outcome between both the groups.

Results are given in tabulated form (Tables 1 to 4).

\section{Discussion}

Intrathecal route of providing labor analgesia has seen a resurrection in recent times. Most frequently used drugs are bupivacaine and fentanyl either alone or in combination. Though useful, this provides either inadequate duration of analgesia (bupivacaine in low dose and concentration) or has prominent side effects (motor blockade leading to higher number of instrumental/operative deliveries). Thus, there is continuous research in novel adjuvants to be given alongside bupivacaine and fentanyl to have long duration analgesia without any motor blockade or other side effects. There is a paucity of literature on the studies comparing intrathecal dexmedetomidine and morphine in labor analgesia. Both these agents have been safely and successfully used intrathecally as well as in pregnant patients for operative deliveries. Therefore we

Table 1: Baseline data

\begin{tabular}{lccc}
\hline Parameters & Group I & Group II & p value \\
\hline Age (in years) & $25.48 \pm 3.601$ & $25.82 \pm 3.703$ & 0.618 \\
$\begin{array}{l}\text { Period of gestation } \\
\text { (weeks } \pm \text { days) }\end{array}$ & $39.08 \pm 1.046$ & $39.08 \pm 1.154$ & 1.000 \\
$\begin{array}{l}\text { Mean cervical dilatation } \\
\text { at time of labor analgesia }\end{array}$ & $4.83 \pm 0.717$ & $4.98 \pm 0.770$ & 0.936 \\
administration $(\mathrm{cm})$ & & & \\
\hline
\end{tabular}

Table 2: Maternal outcomes

\begin{tabular}{lccc}
\hline Parameters & Group I & Group II & pvalue \\
\hline $\begin{array}{l}\text { Mean cervical dilatation } \\
\text { rate (cm/hour) }\end{array}$ & $1.63 \pm 0.135$ & $1.54 \pm 0.156$ & 0.001 \\
$\begin{array}{l}\text { Mean duration of first } \\
\text { stage of labor (minute) }\end{array}$ & $635.25 \pm 61.376$ & $664.47 \pm 50.691$ & 0.005 \\
$\begin{array}{l}\text { Mean duration of second } \\
\text { stage of labor (minute) }\end{array}$ & $48.77 \pm 11.951$ & $50.82 \pm 14.100$ & 0.392 \\
$\begin{array}{l}\text { Mean total duration of } \\
\text { labor (minute) }\end{array}$ & $682.35 \pm 60.920$ & $771.63 \pm 52.016$ & 0.005 \\
$\begin{array}{l}\text { Mean duration of } \\
\text { labor analgesia (minute) }\end{array}$ & $254.42 \pm 13.054$ & $253.50 \pm 13.254$ & 0.703 \\
\hline
\end{tabular}


Intrathecal Labor Analgesia Using Dexmedetomidine

Table 3: Mode of delivery

\begin{tabular}{lccccc}
\hline Type of delivery & $\begin{array}{c}\text { Group I } \\
(N=60)\end{array}$ & Percentage(\%) & $\begin{array}{c}\text { Group II } \\
(N=60)\end{array}$ & Percentage(\%) & p value \\
\hline NVD & 59 & 98.3 & 45 & 75 & 0.001 \\
IVD & 1 & 1.7 & 9 & 15 & \\
NRFHR with poor & 1 & 1.7 & 8 & 13.33 & \\
maternal efforts & & & & & \\
Prolonged second stage & 0 & 0 & 1 & 1.66 & \\
Cesarean & 0 & 0 & 6 & 10 & \\
Fetal bradycardia & 0 & 0 & 2 & 3 & \\
Fetal tachycardia & 0 & 0 & 1 & 2 & \\
Non progress of labor & 0 & 0 & 3 & 5 & \\
\hline
\end{tabular}

Table 4: Fetal outcome

\begin{tabular}{lccc}
\hline Neonatal parameter & $\begin{array}{c}\text { Group I } \\
(N=60)\end{array}$ & $\begin{array}{c}\text { Group II } \\
(N=60)\end{array}$ & p value \\
\hline APGAR score at 1 minute & $7.10 \pm 0.440$ & $7.17 \pm 0.587$ & 0.483 \\
APGAR score at 5 minutes & $8.83 \pm 0.376$ & $8.82 \pm 0.390$ & 0.812 \\
Neonatal resuscitation & No & No & - \\
NICU admissions & No & No & - \\
\hline
\end{tabular}

intended to use and study these drugs in intrathecal dosage for labor analgesia in view of maternal and neonatal outcomes.

The mean cervical dilatation rate in the present study in group I was $1.63 \pm 0.135 \mathrm{~cm} /$ hour and in group II was $1.54 \pm 0.156 \mathrm{~cm} /$ hour, which interestingly is faster than normal. Other studies also support the fact that intrathecal analgesia may provide for quicker cervical dilatation, thus giving it another advantage. In a study Gehan et al. ${ }^{6}$ while evaluating the effect of intrathecal dexmedetomidine on quality of CSE analgesia on labor outcome, the rate of cervical dilatation was found to be at least $1.6 \pm 0.2 \mathrm{~cm} / \mathrm{hour}$. The same was substantiated by Hess et al. ${ }^{7}$ in their study of spinal labor analgesia using bupivacaine/fentanyl/morphine (BFM). It may be due to the fact that it leads to muscle relaxation.

The mean duration of second stage of labor was $48.77 \pm 11.951$ minutes in group I and $50.82 \pm 14.1$ minutes in group II, respectively. Duration of second stage of labor in the study conducted by Viitanen et al. ${ }^{8}$ was $9.6 \pm 10.7$ minutes, and it could be attributed to difference in parity. In a study conducted by Mathur et al., ${ }^{2}$ it was significantly less compared to the present study. The intrathecal analgesia protocol was a bit different in that study. Although bupivacaine and fentanyl were given in similar doses, injection morphine or dexmedetomidine was not administered for intrathecal labor analgesia. Moreover, the baseline parturients characteristics and the neonatal birth weight details are not available in that study and these parameters also affect the duration of labor.

In the present study the mean total duration of labor in group I was $682.35 \pm 60.92$ minutes and $711.63 \pm 52.016$ minutes in group II. Similar to our study, the study by Dostbil et al. ${ }^{9}$ on the effects of adding morphine to bupivacaine for labor analgesia found that the duration of labor was more in group bupivacaine/fentanyl/ morphine (BFM) (852.86 \pm 342.2 minutes) as compared to group BF (758.07 \pm 382.1 minutes). Results of this study are more comparable to the study conducted by Hess et al. ${ }^{7}$ to assess the effect of small dose of spinal bupivacaine/fentanyl alone or in combination with a small dose of morphine $(125 \mu \mathrm{g})$ as labor analgesia. The duration of labor was $322 \pm 139$ minutes, in group $B F$ and $432 \pm 272$ minutes, in group BFM. The study by Yeh et al. ${ }^{10}$ to determine the effect of addition of morphine $(150 \mu \mathrm{g})$ to the intrathecal combination of fentanyl $(25 \mu \mathrm{g})$ and bupivacaine $(2.5 \mathrm{mg})$ on duration of labor analgesia found that the mean duration of labor was $9.46 \pm 4.5$ hour in group BF and it was $9.96 \pm 5.8$ hour in group BFM.

The mean duration of analgesia in the present study in group I was $254.42 \pm 13.054$ minutes and $253.50 \pm 13.254$ minutes in group II. It was longer as compared to the studies conducted by Owen et al. ${ }^{11}$ (90 \pm 21 minutes), Nelson et al. ${ }^{12}$ (79 \pm 34 minutes), Viitanen et al. ${ }^{8}$ (101 \pm 34 minutes), and Mathur et al. ${ }^{2}$ (108 \pm 20 minutes). The difference can be attributed to the administration of morphine and dexmedetomidine in addition to bupivacaine and fentanyl in the present study whereas the intrathecal labor analgesia comprised only bupivacaine and fentanyl in the rest of the studies.

Results of our study are similar to the study conducted by Yeh et al., ${ }^{10}$ where they found that addition of morphine to bupivacaine and fentanyl combination increases the duration significantly $(252 \pm 63$ vs $148 \pm 44$ minutes).

The result of our study was in accordance with Minty et al., ${ }^{13}$ who in a clinical review based on 33 articles including 14 studies, 1 meta-analysis, and 2 systemic reviews, all providing level I evidence concluded that a combination of $2.5 \mathrm{mg}$ bupivacaine, $25 \mu \mathrm{g}$ fentanyl, and $250 \mu \mathrm{g}$ of morphine intrathecally provides a 4 hour window of acceptable analgesia.

Thus it is evident from the above studies that intrathecal morphine/dexmedetomidine in addition to their own analgesic action have the synergistic effect on bupivacaine and fentanyl which results in prolongation of analgesia with lowest possible doses.

In the present study group I had $98.3 \%$ (59/60) NVD, 1.7\% (1/60) IVD, and none had cesarean delivery. Similarly in group II, 75\% $(45 / 60)$ had NVD, 15\% (9/60) had IVD, and 10\% (6/60) had cesarean delivery. The cumulative results are in line with normal accepted obstetric parameters. Overall caesarean rate in the present study was $10 \%$ among the parturients receiving single-shot intrathecal labor analgesia as morphine (group II), which was similar to the study by Hess et al. ${ }^{7}$ to assess the effect small dose of spinal bupivacaine/fentanyl alone or in combination with a small dose of morphine $(125 \mu \mathrm{g})$ as labor analgesia in which rate of cesarean delivery was $14 \%$. In the study conducted by Nelson et al. ${ }^{12} 55 \%$ delivered vaginally, $21 \%$ had IVD and the remaining $24 \%$ underwent caesarean section. In another study by Gehan et al. ${ }^{6}$ on the effect of intrathecal dexmedetomidine on the quality of combined spinal epidural analgesia observed that $10 \%$ patients had instrumental delivery and $6.7 \%$ had cesarean delivery and $84.3 \%$ patients had 
normal vaginal delivery. In the study done by Madishetti et al., ${ }^{14} 75 \%$ patients delivered vaginally, $12.5 \%$ had assisted vaginal delivery, and $12.5 \%$ delivered by LSCS. Similarly in study done by Shah et al., ${ }^{15}$ $12 \%$ had IVD,64\% had NVD and $24 \%$ had cesarean delivery.

In the present study, none of the parturients in either group had any significant side effects which is supported by other studies using similar doses. ${ }^{4,16-22}$

The mean APGAR scores in group I at 1 and 5 minutes were $7.10 \pm 0.440$ and $8.83 \pm 0.376$, respectively, and the mean APGAR scores in group II at 1 and 5 minutes were $7.17 \pm 0.587$ and $8.82 \pm 0.390$, respectively. None of the neonates required NICU admission in the two groups. The insignificant effect of our intrathecal analgesia protocol on neonate is also substantiated by other studies using similar dosage. 4,17,19,23-26 $^{-2}$

\section{Conclusion}

The present study shows that the single-shot intrathecal labor analgesia using the combination of bupivacaine $(2.5 \mathrm{mg})$, fentanyl $(25 \mu \mathrm{g})$, and morphine $(250 \mu \mathrm{g})$ or dexmedetomidine $(5 \mu \mathrm{g})$ is a viable method of pain relief in labor and delivery. The reliability of spinal block, in terms of achieving satisfactory analgesia within a reasonable time limit and providing adequate analgesia till the end of delivery, is the most important issue to address. Single-shot spinal analgesia provides a 3-4 hours window of pain relief in labor and delivery. Therefore, it may provide an adequate analgesia to parturients till delivery when administered in the active phase of labor.

Single-shot intrathecal labor analgesia using the combination of bupivacaine $(2.5 \mathrm{mg})$, fentanyl $(25 \mu \mathrm{g})$, and dexmedetomidine $(5 \mu \mathrm{g})$ is a safe, effective, reliable, cheap, and satisfactory method of pain relief for labor and delivery. Moreover, it is devoid of side effects on mother and fetus. It is also associated with rapid cervical dilatation.

\section{References}

1. Choudhary J, Sharma H, Acharya V. Maternal and fetal outcome in epidural analgesia study. Int J Reprod Contracept Obstet Gynecol 2016;5(10):3547-3551. DOI: 10.18203/2320-1770.ijrcog20163441.

2. Mathur P, Jain N, Prajapat L, et al. Effect of intrathecal analgesia using fentanyl and bupivacaine on progress of labor. J Obstet Anaesth Crit Care 2018;7(1):47-51. DOI: 10.4103/2249-4472.194297.

3. Westgren M, Lindahl SGE, Norden NE. Maternal and fetal endocrine stress response at vaginal delivery with and without an epidural block. J Perinatal Med 1986;14(4):235-241. DOI: 10.1515/ jpme.1986.14.4.235.

4. Fyneface-Ogan S, Gogo Job O, Enyindah CE. Comparative effects of single shot intrathecal bupivacaine with dexmedetomidine and bupivacaine with fentanyl on labor outcome. ISRN Anesthesiol 2012; 2012:1-6. DOI: 10.5402/2012/816984.

5. Grewal A. Dexmedetomidine: new avenues. J Anaesthesiol Clin Pharmacol 2001;27(3):297-302. DOI: 10.4103/0970-9185.83670.

6. Gehan FE, Heba MF, Hussein M, et al. Effect of intrathecal dexmedetomidine on the quality of combined spinal epidural analgesia and obstetric outcome during vaginal delivery. Res Opin Anaesth Intensive Care 2017;4(1):23-28. DOI: 10.4103/2356-9115.202696.

7. Hess PE, Vasudevan A, Snowman C, et al. Small dose bupviacainefentanyl spinal analgesia combined with morphine for labor. Anaesth Analg 2003;97(1):247-252. DOI: 10.1213/01.ane.0000066520.30763.b8.

8. Viitanen $\mathrm{H}$, Viitanen M, Heikkila M. Single-shot spinal block for labour analgesia in multiparous parturients. Acta Anaesthesiol Scand 2005;49(7):1023-1029. DOI: 10.1111/j.1399-6576.2005.00803.x.
9. Dostbil A, Celik M, Alici HA, et al. Maternal and neonatal effects of adding morphine to low-dose bupivacaine for epidural labor analgesia. Niger J Clin Pract 2014;17(2):205-210. DOI: 10.4103/11193077.127559.

10. Yeh HM, Chen LK, Shyu MK, et al. The addition of morphine prolongs fentanyl-bupivacaine spinal analgesia for the relief of labor pain. Anaesth Analg 2001;92(3):665-668. DOI: 10.1097/00000539200103000-00022.

11. Owen MD, Ozsarac O, Sahin S, et al. Low-dose clonidine and neostigmine prolong the duration of intrathecal bupivacaine fentanyl for labor analgesia. Am Soc Anaesthesiol 2000;92(2):361-366. DOI: 10.1097/00000542-200002000-00016.

12. Nelson KE, Rauch T, Terebuh V, et al. A comparison of intrathecal fentanyl and sufentanil for labor analgesia. Am Soc Anesthesiol 2002;96(5):1070-1073. DOI: 10.1097/00000542-200205000-00007.

13. Minty RG, Kelly L, Minty A, et al. Single-dose intrathecal analgesia to control labour pain. Is it a useful alternative to epidural analgesia? Can Fam Physician 2007;53(3):437-442. PMID: 17872679.

14. Madishetti ER, Aasim SA. A comparative prospective study of intrathecal dexmedetomidine-fentanyl for labor analgesia. J Adv Med Dent Sci Res 2018;6(1):93-97. DOI: 10.21276/jamdsr.

15. Shah V, Bajaj M, Verma J. Randomized comparative study of intrathecal administration of dexmedetomidine-fentanyl for labour pain. Natl J Integr Res Med 2018; 9(1):88-91. Retrieved from: http:// nicpd.ac.in/ojs-/index.php/njirm/article/view/1859.

16. Dilesh PK, Eapen S, Kiran S, et al. A comparison of intrathecal dexmedetomidine verses intrathecal fentanyl with epidural bupivacaine for combined spinal epidural labor analgesia. J Obstet Anaesth Crit Care 2014;4(2):69-74. DOI: 10.4103/2249-4472.14 3875.

17. Samal S, Pattnaik SK, Mohta A, et al. Intrathecal dexmedetomidine versus morphine as adjuvant to bupivacaine in LSCS. Indian J Clin Anaesth 2016;3(4):607-610. DOI: 10.18231/2394-4994.2016.0023.

18. Gupta R, Verma R, Bogra J, et al. A comparative study of intrathecal dexmedetomidine and fentanyl as adjuvants to bupivacaine.J Anaesthesiol Clin Pharmacol 2011;27(3):339-343. DOI: 10.4103/09709185.83678.

19. Tshibuyi PN, Olang POR, Ogutu O, et al. A comparative study on the efficacy of two regimens of single-shot spinal block for pain relief in women presenting in established labour. East Afr Med J 2013;90(1):12-18. PMID: 26862625.

20. Anabah T, Olufolabi A, Boyd J, et al. Low-dose spinal anaesthesia provides effective labour analgesia and does not limit ambulation. South Afr J Anaesth Analg 2015;21(1):19-22. DOI: 10.1080/22201181.2015.1013322.

21. Girgin NK, Gurbet A, Turker G, et al. Intrathecal morphine in anaesthesia for cesarean delivery: dose-response relationship for combinations of low dose intrathecal morphine spinal bupivacaine. J Cin Anesth 2008;20(3):180-185. DOI: 10.1016/j. jclinane.2007.07.010.

22. Singh SN, Subedi A, Prasad JN, et al. Effect of intrathecal bupivacaine with morphine or butorphanol. Health Renaissance 2013;11(3): 246-249. Available from: https://doi.org/10.3126/hren.v11i3.9640.

23. Dani C, Perugi S, Fontanelli G, et al. Effects of epidural and systemic maternal analgesia in term infants: the NoPiL study. Front Biosci (Elite Ed) 2010;2:1514-1519. DOI: 10.2741/e210.

24. Eid HE, Shafie MA, Youssef H. Dose related effect of intrathecal dexmedetomidine with hyperbaric bupivacaine - a prospective randomized double blind study. Ain Shams J Anesthesiol 2011; 4:83-95.

25. Nair AS, Sriprakash K. Dexmedetomidine in pregnancy: review of literature and possible use. J Obstet Anaesth Crit Care 2013;3(1):3-6. DOI: 10.4103/2249-4472.114253.

26. Palanisamy A, Klickovich RJ, Ramsay M, et al. Intravenous dexmedetomidine as an adjunct for labor analgesia and cesarean delivery anesthesia in a parturient with a tethered spinal cord. Int J Obstet Anesth 2009;18(3):258-261. DOI: 10.1016/j.ijoa.2008.10.002. 